\title{
Presentación de un caso y revisión de la literatura
}

José Ignacio Hernández Cruz, MD*

\section{Resumen}

Se trata de una mujer joven que consultó por dolor abdominal intenso de tres horas de evolución acompañado de náuseas y vómito que no mejoró con analgésicos ni antiespasmódicos, por lo cual acudió al médico que le formuló aines, antiespasmódicos y analgésicos sin obtener mejoría. Se interconsultó al gastroenterólogo quien realizó endoscopia de vías digestivas altas diagnosticando severa pangastritis. Recibió medicación con omeprazole y ranitidina sin aliviarse. Los laboratorios clínicos de cuadro hemático, parcial de orina, glicemia, creatinina y nitrógeno ureico no revelaron alteraciones. Un día después notaron trastornos neurológicos y cuadro convulsivo que se estudió con TAC cerebral en tres ocasiones, interpretados como normales. Los análisis del líquido cefaloraquídeo en varias oportunidades permanecen dentro de los parámetros usuales. Se cultivan con el interés de encontrar una causa infecciosa con datos negativos. En laboratorios seriados aparece hiponatremia severa, por lo cual se remite al endocrinólogo y la estudian para trastorno suprarenal cuyos resultados son normales. Se interconsulta a nefrología que ordena estudiar y descartar neuropatía. En la unidad de cuidados intensivos se maneja con anticonvulsionantes, analgésicos, antipiréticos, solución salina y antibióticos. Como no hay respuesta a la terapia indicada y los resultados del laboratorio fueron negativos para enfermedad infecciosa del sistema nervioso central o renal, le practicaron estudios ecocardiográficos con resultados normales y hemocultivos negativos. Se consulta al servicio de medicina interna que después de revisar la historia clínica realiza un examen físico detenido y analizar todos los estudios, ayudas paraclínicas y la opinión de los distintos especialistas, considera descartar porfiria intermitente aguda. Se traslada de nuevo a la UCI con resultados en orina positivos para el diagnóstico propuesto.

Palabras clave: porfiria, trastorno metabólico, hiponatremia.

Abreviaturas: PF, porfiria.

\section{Introducción}

Escribir sobre esta enfermedad de diagnóstico difícil debido a su baja incidencia requiere agudeza clínica, porque existen otras patologías que con síntomas parecidos desvían el diagnóstico.

Porfirias. La PF es un trastorno hereditario o adquirido, causado por deficiencia enzimática de la vía biosintética del hem. Los productos intermediarios

Fecha recibido: 8 de septiembre de 2006 -Fecha aceptado: 30 de noviembre de 2006.

* Médico internista cardiólogo, Profesor Titular Universidad del Rosario y Fundación Universitaria de Ciencias de la Salud. Jefe del área clínica de la FUCS. Miembro de número de la Sociedad de Cardiología.

Miembro honorario de la Sociedad de Cardiología.

Miembro de número de la Sociedad Colombiana de Medicina Interna.

Miembro de número de la Sociedad de Cirugía de Bogotá, Hospital de San José. de esta vía se conocen como porfirinas, con moléculas dotadas de cuatro anillos pirrólicos limitados por puentes de carbono. El centro de esta estructura fija con facilidad metales como hierro, magnesio y cobalto. En los mamíferos, las porfirinas funcionan exclusivamente como complejos metálicos (hem con hierro y vitamina B12 con el cobalto).

En general la producción del hem es tan eficiente que los intermediarios de su síntesis se metabolizan con rapidez, de modo que menos del 1\% son detectados en la sangre. Cuando en la orina o las heces aparecen cantidades aumentadas de porfirinas o sus precursores, existe una perturbación de estas y las anormalidades metabólicas resultantes se conocen colectivamente como porfirias. 
El hem tetrapirrol que contiene ión ferroso es el centro funcional de las hemoglobinas, mioglobinas, catalasas, peroxidasas y citocromos y participa en el proceso general de la respiración oxidativa. Los porfirinógenos son intermediarios en la vía sintética que va desde el ácido delta-aminolevulínico (ALA) hasta el hem. La porfirina es la forma oxidada del porfirinógeno.

Existen ocho enzimas primarias asociadas con la via biosintética del hem. Las anormalidades en cualquiera de ellas puede permitir acumulación de metabolitos previos, y por ende, las manifestaciones clínicas de la PF.

Para entender la fisiopatología de las diversas PF y favorecer el manejo de los métodos de diagnóstico, es importante recordar que la vía funciona en la mitocondria y en el citoplasma. Por lo tanto, si la presunta deficiencia enzimática es citoplasmática, se pueden determinar las enzimas eritrocitarias porque los eritrocitos tiene un citoplasma adecuado. Sin embargo, como tienen pocas mitocondrias, para determinar las enzimas que actúan en éstas, se requieren muestras de materia fecal para establecer el diagnóstico.

Todas las PF hepáticas son trastornos autosómicos dominantes. Se clasifican como:

\section{Porfirias hepáticas:}

-Aguda Intermitente

-Cutánea tarda

-Coproporfiria hereditaria

-Porfiria variegata

\section{Porfirias eritroides:}

-Eritropoyética

\section{-Congénita}

La fotosensibilidad solar en la piel es común a todas las PF, excepto la aguda intermitente, porque el metabolito tóxico excretado es un pirrol y no una porfirina. En ésta, las mujeres están afectadas con mayor frecuencia. La presencia de dolor abdominal y manifestaciones neurológicas indican el carácter agudo de la PF. Todas estas son enfermedades agudas, menos la cutánea tarda.

\section{Los síntomas de la PF intermitente aguda son:}

-Dolor abdominal tipo cólico, estreñimiento, íleo.

-Trastorno mental.

-Debilidad muscular.

-Retención urinaria.

-Convulsiones.

-Hipertensión arterial.

-Taquicardia.

La activación de la enfermedad guarda relación con factores ambientales, hormonales, fármacos, dietas y esteroides.

\section{Presentación del caso}

Mujer de 22 años de edad, natural y residente en Bogotá, procedente de Villavicencio es remitida de una clínica de la misma ciudad, donde permaneció por cinco días. La enfermedad se inició diez días antes por cefalea, malestar general y fiebre de 38 grados y se medica con acetaminofén y diclofenaco intramuscular. Posterior a esto acusa emesis en ocho ocasiones requiriendo manejo con ranitidina y omeprazol, sin mejoría. Se realiza esofagogastroduodenoscopia que informa pangastritis, hernia hiatal y helicobacter pylori.

Se agrega sucralfate y metoclopramida sin mejoría. Cuatro días después de su ingreso presenta en dos ocasiones convulsiones tonicoclónicas generalizadas, por lo cual se aplica valium y fenitoína posictal sin recuperación de la conciencia y espasticidad de hemicuerpo derecho. Se lleva a la UCI y se realizan estudios del sistema nervioso central para descartar daño estructural y líquido cefaloraquídeo por la posibilidad de infección. La tomografía y la resonancia son normales, así como también el líquido.

Laboratorio: cuadro hemático, bilirrubinas y transaminasas normales, hiponatremia severa e hipocalemia leve. Se hidrata con solución salina, 
cloruro de potasio endovenoso, fenitoína y midazolam. No mejora ni la hiponatremia ni la hipocalemia y hace cuadro de excitación sicomotora; se agrega cefepime e hidrocortisona por sospecha de insuficiencia suprarrenal.

Revisión por sistemas: episodios de mialgias y epigastralgia recurrentes de 18 meses de evolución. Parestesias en manos, bilaterales, en tres oportunidades desde hace un año. Hábitos intestinal y urinario normales.

Antecedentes: tratada de tiempo atrás por gastritis con omeprazol, amoxacilina y claritromicina. Go Po Ao, fractura antigua carpiana derecha.

Examen físico: persona somnolienta con agitación sicomotora, presión arterial 120-70, mm Hg, frecuencia cardíaca 112 por minuto, frecuencia respiratoria 22. Pupilas isocóricas normales. Cuello y cardiopulmonar sin alteraciones. Abdomen con dolor difuso a la palpación profunda, extremidades, reflejos tendinosos y pares craneanos normales.

Ingresa a la UCI en Bogotá para reposición de líquidos y electrolitos, se continúa medicación con fenitoína, medozolam, haloperidol, alprazolam y dipirona. Nuevos exámenes de laboratorio muestran normalidad en cuadro hemático, hemoglobina, hematocrito, calcio, cloro, pruebas renales, tiempos de protrombina y parcial de tromboplastina, glicemia y plaquetas. Hay leucocitosis, con neutrofilia y el sodio en orina ese halla aumentado. Se pide opinión y ayuda a los servicios de nefrología y endocrinología que conceptúan: insuficiencia suprarenal y secreción inadecuada de hormona antidiurética. Los niveles séricos de cortisol y ACTH son normales. Se realiza de nuevo punción lumbar que descarta enfermedad infecciosa. Una nueva resonancia nuclear magnética es normal.

Mejora la hiponatremia, sale de UCI y en el piso aparecen de nuevo síntomas de excitación, dolor abdominal y no mejora su cuadro neurológico, presentando polipnea, taquicardia de 130 por minuto, hiponatremia y en el cuadro hemático severa leucocitosis. Las radiografías del tórax y el parcial de orina normales, los hemocultivos negativos. Se intercolsulta a medicina interna, que al revisar con detención la historia y el cuadro clínico, sospecha el diagnóstico de porfiria intermitente aguda.

Se solicitan pruebas adicionales en muestras de 24 horas: ácido delta-aminolevulínico $182.5 \mathrm{mg}$ (normal entre 1 y $7 \mathrm{mg}$ ), coproporfirinas 203 microgramo (normal de 0 a 160) y porfobilinógeno $3.9 \mathrm{mg}$ (normal de 0 a 2). Se confirma el diagnóstico y se inicia tratamiento con el panhematin. En el manejo de la UCI presenta múltiples complicaciones y sobreinfección que requieren de ayudas ventilatorias $\mathrm{y}$ nutricionales.

\section{Discusión}

La lectura de esta historia es a todas luces evidente de la dificultad que existe para el cuerpo médico de hacer el diagnóstico temprano. Los síntomas en esta enfermedad suelen confundir a los clínicos, con problemas agudos abdominales como se pone de presente en este caso, en el cual fue sometida a múltiples estudios paraclínicos y endoscopia, considerándose diagnósticos de procesos no específicos como pangastritis y H.pylori y a ser manejados con omeprazol. Estos hallazgos son la consecuencia de la medicación prescrita anteriormente para su dolor abdominal no específico. Después aparece el fenómeno convulsivo y los trastornos neurológicos analizados, y las ayudas diagnósticas tanto de laboratorio clínico, de imágenes (TAC, resonancia) como del líquido cefalorraquídeo son normales, lo cual permite excluir un proceso infeccioso. Obsérvese que la medicación prescrita para su problema neurológico central está agravando su cuadro.

Como no hay mejoría, se vuelven a realizar imágenes, punción lumbar, hemocultivos, con el interés y la esperanza de encontrar enfermedad infecciosa, lo cual resulta negativo. En la toma de los electrolitos aparece hiponatremia y por esta razón se piensa en problemas suprarenales y se estudia para ello, con resultados normales. En ese momento es evidente que la paciente 
inicia la enfermedad con un problema abdominal seguido de trastornos neurológicos importantes, una baja del sodio y taquicardia (130 x min). Con estas tres condiciones y por pertenecer al sexo femenino, es necesario que entre en el diagnóstico diferencial la posibilidad de porfiria intermitente aguda.

Practicados los estudios, como reporta la historia, se confirma el diagnóstico quince días después de haber iniciado su crisis aguda y es de todos conocido que entre más retardado el diagnóstico, más lenta la recuperación de sus daños neurológicos. Al desconocerse la causa, el tratamiento sintomático de estas personas obliga a dar medicamentos que están contraindicados, porque pueden precipitar o agravar su crisis, tales como barbitúricos, sulfamidas, moprobamato, mefenitoína, carbamazepina, ácido valproico, pirazolonas, ergotamina, estrógenos y gestágenos sintéticos, alcohol y muchas otras más. Estas personas pueden presentarse también con trastornos neurosiquiátricos, taquifilaxias 0 hipertensión, debilidad muscular y estreñimiento más que diarrea. Los síntomas abdominales se explican por neuropatía del sistema autónomo visceral inducida por metabolitos neurotóxicos. Conviene recordar que situaciones como la inanición, las dietas y los trastornos de ansiedad, pueden desencadenar episodios agudos. La fotosensibilidad no está presente en la porfiria intermitente aguda porque el metabolito tóxico excretado es un pirrol y no una porfirina.

El tratamiento se hace especialmente con hematina por vía intravenosa, que acrecienta el pool hepático de hem libre y reprime la actividad de ALA sintetasa. Esta sustancia sólo está indicada en los episodios agudos con trastornos neurológicos, pero en manifestaciones menos severas, se pueden usar analgésicos y soluciones parenterales con alto contenido de glucosa. La respuesta al tratamiento con hemo es menor si el diagnóstico se realiza tarde. Se puede administrar hematina, hemoalbúmina o hemoarginato, que son estables químicamente.
Se pueden usar medicamentos tales como analgésicos narcóticos, acido acetilsalicílico, fenotiazinas, penicilinas, glucocorticoides, bromuros y atropina, que no precipitan crisis de porfiria.

Las enfermedades de difícil diagnóstico y de infrecuente presentación, exigen historia clínica completa, examen físico total y una valoración adecuada de los síntomas, que como en esta patología, sugieren el diagnóstico.

\section{Lecturas recomendadas}

-Elder GH, Hift RJ, Meissner PN. The acute porphyrias. Lancet. 1997; 349:1613-7.

-Elder GH, Hift RT, Neissner PN. The acute porphyries. Lancet. 1997; 349:82-3.

-González-Arriaza HL, Bostwick JM. Acute porphyrias: a case reportand review. Am J Psychiatry. 2003; 160:450-8.

-Kauppinen R, Mustajoki P. Prognosis of acute porphyria: occurrence of acute attacks, precipitating factors, and associated diseases. Medicine. 1992; 71:1-13.

-Moore MR, McColl KE, Fitzsimons EJ, Goldberg SA. The porphyrias. Blood Rev. 1990;4:88-96.

-Sassa S, Kappas A. The porphyrias. [serie en Internet]. 2003 [citado 1 Mayo 2004];9: [aprox 3 p.]. Disponible en: WebMD Inc.

-Thadani H, Deacon A, Peters T. Diagnosis and management of porphyria. BMJ. 2000;320:1647-51.

-Teague A. Dombeck, MD, Robert C. Satonik, MD, The Porphyrias Emerg Med Clin N Am 23; 2005 885-899.

-Werman H. The porphirias. Emerg Clin North Am. 1989;7(4):927-42.

-Yueh-Ping Liu MD, Wan-Ching Lien MD, Cheng-Chung Fang MD, Ting-I Lai MD, presentation of acute porphyria. Am J Emerg Med. 2005; 23: 164-67. 